Rena T. Gasimova

DOI: $10.25045 / j p i s . v 08.11 .08$

Institute of Information Technology of ANAS, Baku, Azerbaijan

renakasumova@gmail.com

\title{
SOME FEATURES OF DEVELOPING ELECTRONIC LIBRARIES
}

\begin{abstract}
The creation of e-library reflects a new quality level in various data storage, systemization and distribution. The article describes the creation and accessibility issues of e-library. It also studies the transition from traditional libraries to e-libraries, and analyses the main objectives and characteristics of national e-libraries and presents some recommendations.
\end{abstract}

Keyword: Information technology, electronic information, electronic library, electronic document, electronic catalog, library funds.

\section{Introduction}

In a dynamic developing society, information acts as wealth and power, as well as an important strategic resource. The global process called "Informatization" affects all the fields of the society. The main feature that characterizes this process is the status of the information as one of the major factors of the existence of the civilization. Today, economic and social success is more accessible to those countries that actively use the modern communication and networking devices, information technologies and information resource management systems.

Electronic information resource is one of the main attributes of the information society. The provision of the access to electronic information has become one of the most important challenges of the information services of science and education. Information technology has created opportunities to turn the large-scale information collected by the humanity into electronic form in principal, of generating new type of information resources related to electronic libraries. It should be noted that electronic information has changed the relevant social needs resulting in completely transformed libraries. It is becoming a powerful and important area of information industry equipped with new computer technologies, non-traditional information carriers, and highly efficient automated technologies for the data processing and use.

The application of the technologies, which are the basis of the creation of digital libraries, creates new opportunities for the management and processing of large-scale data. That is, information resources converted into electronic form and collected in a single system acquire a new status. In this case, new methods of generation, storage, processing, organization and distribution of various forms of information (text, graphics, audio, video, etc.) are implemented, so that the wider distribution and efficient use of information is provided. The introduction of information technology is changing the role of libraries in society, expanding and complicating their functions and duties. At present, electronic libraries are the cornerstones for the creation of the new information infrastructure. Because, e-libraries, as rather sustainable social institutions, are capable to take responsibility for the socialization of the cultural and scientific segment of electronic information space [1]. The article examines the creation, efficiency and organizational principles of electronic libraries.

\section{e-Library creation issues}

Today, the creation processes of electronic libraries and related information infrastructure have widely spread all over the world. The creation and use of e-libraries is realized through the collection, storage, registration and structuring electronic data. In other words, electronic library provides the navigation through the information space, and with the help of telecommunications networks any number of readers access them $[2,3]$.

Electronic Libraries are alternative to the automation technology of neither traditional nor library processes. Thedevelopment of new libraries, first of all, is scanning a part of its collection, systemizing and organizing them, and serving to local and remote users. No electronic library can 
replace electronic catalog, documents return, filing, registration and search engine and other components of the automated technology. Electronic Libraries are designed to extend a wide range of services offered to the library users and to present new service for document delivery. Studies show that the following problems need to be solved for the successful electronic libraries [4]:

- Technological- electronic documents' description issues (description rules, completions of bibliographic records format, defining the decision on issuing unique identifiers to electronic documents,); library registration of electronic publications created and stored on the servers of other organizations; The organization's long-term preservation of electronic library fund;

- Technical- digitalization methods of traditional publishing; methods for the conversion of the original models of the publishers into the format adopted by the electronic libraries; prevention tools for unauthorized access to the e-library funds; electronic document storage technology; payment control for the right to get familiarized with electronic documents;

- Legal- applying copyright to electronic documents; features of applying the national laws in case of third party accessibility to electronic documents.

In traditional libraries, the specialization was defined only by the selection of the literature, while in electronic libraries, it was defined by the storage facilities or additional software sets for the implementation of this or that manipulation. Any library can even be fragmentally electronic, i.e., the database is partially digitalized [5].

Electronic library can be two-level, namely, it can contain electronic catalog and electronic versions of books' texts. Such libraries are carried out on the personal computers of different configurations, which are technically united in the local network and controlled by the network operating system. The texts of machine-readable books (publications readable with special apparatus) obtained from the publishing houses are checked by the operator-correctors and compared with the printed edition for their subsequent use by the readers. Revised e-texts of the books are archived and included into the e- library. During the projection of e-libraries, especially in the case of multilingual publications with texts and graphical information, the problem of data storage and presentation formats arises. The studies demonstrate that all electronic libraries are formed based on the followings [6,7]

- Purposeful or custom digitalization;

- Computer preparation of publications for the spread in traditional and electronic environment;

- Technologies to work only electronically.

All of them are the technologies for the preparation of electronic resources and the digitization of traditional resources. These approaches focus on the performance of the e-library functions.

\section{e-Library efficiency and organizational principles}

Today, available libraries can function not only with the traditional information resources, but also with the digital information (the network and non-network). Most libraries have their own web servers; furthermore, many of them are engaged in the creation of unique number collections. Despite the strenuous growth trend of generating electronic resources in libraries, they mainly remain as the center and their main function is to provide the users with efficient and timely access to information [8].

According to the form and content of the various electronic resources, the increase in their quantity is impossible to be identified by any dependence. In addition, electronic resources differ from one another for their realization forms and distribution resources. The libraries should tackle the problem of lack of unified access to electronic resources, should evaluate their reliability and relevance, which will dramatically increase the quality of information services. Experts tend to include the following features that characterize the effectiveness of electronic libraries [9]: 
- book collection maintenance and the use of the machine-readable copies of the documents solve the main library problem by preventing the deterioration of their original;

- information requests of the library users are fully satisfied, and a user gets the information whenever and wherever;

- the efficiency of presenting the required document and information to the users is significantly increasing;

- new image of the library offering information in non-traditional media is formed, and the significance of the library performance is increasing;

- the information culture of the readers, library staff and their computer literacy rate is rising, and it is of great importance as the highly information cultured man can be more easily oriented in constantly changing environment and is not afraid of innovations and changes;

- multimedia devices presenting text, audio and video data enable to better understand the materials, so that the information is accepted as a whole, that is, by numerous senses at the same time.

\section{The main duties of the national e-Library}

Society is responsible for the protection of the world's cultural heritage against the future generations. This is very important at the present time, when the danger of destruction of preserved documents as a result of the global economic and political instability has increased, and ecological conditions, natural disasters and industrial accidents occur. World libraries are storing more than billions of various documents - manuscripts, printed, audio-visual, electronic and other data, so that their physical condition is causing great excitement [10-12].

National e-Libraries (NEL) focus on the collection of national electronic heritage and its delivery to the users. Studies show that the process of e-library formation of each country has become long-lasting, and this factor poses real grounds for the formation of a national library and information fund of electronic documents. Currently, large volumes of e-libraries are available in different languages on the Internet, and these digital data banks contain newspapers, journals, and analytical reports. Public information systems as NEL have been existed and actively used in the Western countries for a long time. One of such large-scale projects is the digitization of the Vatican Library treasures (it stores the first 8 thousand published books, 150 thousand manuscripts (handwritten), 1 engraving, 300 currency samples, etc.) [13-15].

Experts note that NELs are predominantly focusing on the important issues as the development and application of integrated, distributed and automated library and information center. It provides the support for the lifecycle of the digital documents by cumulating electronic resources of the libraries and other funds to all categories of users and ensures the followings [16, 17]:

- building the National Foundation for electronic documents, providing their collection and long-term maintenance;

- developing single query and search engine at all parts of NEL fund - it opens up its content and allows the end-user implementing multi-aspect search or using navigation tools;

- ensuring users' access to electronic documents;

- developing operative information system about the NEL's performance, its resources and services, as well as usage rules and conditions.

The tasks set forth can be achieved by the fulfillment of the following main functions:

- information oriented to the need for the provision of information demand of the users of different categories in all the fields of knowledge;

- education through the promotion of the books, manuscripts (manuscripts) and other document about the history and culture of any country;

- research aimed at in-depth study of the subject (subject)by high level of researchers and experts; 
- educational - supporting formal and non-formal education through the promotion of not only textbooks, but also additional necessary literature as authoritative monographs.

Today, the safety of libraries is of paramount importance both in the virtual and physical space. According to experts, a library's security implies its protection as a certain material objection the one hand, and as a social institution, i.e., as an object of the social infrastructure of the society on the other hand. In a broad sense, the library's security is the protection of all its containing elements. The protection implies the neutralization of negative factors affecting the functioning of the library. At present, library funds preservation issues are in the scope of the library experts from all countries. Even back in the XIX century, different methods for conservation of documents were developed in the United States, Great Britain, Italy, France, Sweden, Germany and India. Some of them are still in use [18-20].

By its nature, the Internet opens up great prospects for traditional libraries as for virtual libraries and information agencies. The deployment of library servers and uploading unique library and information resources and services in the network provides the readers all over the world to access electronic catalogs of libraries and documents and so on.

\section{Conclusion}

Today, we can say that most libraries are dealing with the electronic data collection. However, none of them is capable to collect periodical publications (both traditional and electronic) all over the world in one place. Analysis of international experience reveals that the use of electronic publications is one of the main activities of the libraries. Hence, it enables them to eliminate the problem of subscriptions to periodicals in the traditional way. The libraries are united in the consortium to solve this problem; in this case, they get more financially favorable joint access to the journals or publications of a certain publishing house rather than the separate subscription.

Thus, time shows how useful the electronic libraries are. It should be noted that the library support environments are being developed in many countries. Furthermore, electronic collections and funds collecting more valuable and socially important information are developed and included into the electronic library resources (ELR). The organizational and technological infrastructure is developed for ELR performance, and inter-institution and regional programs and projects coordination is provided. In ELR, legal documents regulating the relations between individuals and organizations, acting as an information creator, owner and generator, are developed.

\section{References}

1. Golubenko N.B. Information technologies in Library Science. Publishing house Rostov on Don: Phenix, 2012, 287 p.

2. Robb J. Let's read the digital books / / PC World. 1999, No. 2, pp. 36-37.

3. Morgan E. Electronic books, libraries and copyrights // Sc. and techn. library. 2001, No. 8, pp. 27-35.

4. Mogilenko O.N. Technology for creation of electronic library / Libraries and associations in the changing world: new technologies and new forms of cooperation: Tr. Conf., Sudak, 8-16 June 2002, M., 2002, Vol. 1, pp. 231-234.

5. Arms William. Electronic Libraries, University Manual in Informatics and Information Systems, translsted from English by Arnautova S.A. (Lyubertsy): PIC VINITI, 2001, 274 p.

6. Murray R. Components of the Digital Library and Their Interaction, Sc. and techn. library. 2000, No. 6, pp. 56-68.

7. Stepanov V.K.Real and virtual libraries in the era of digital communications // Sc. and techn. library. 2001, No. 1, pp. 71-75. 
8. Impagliazzo J., Cassel L. (Boots), LeeJohn A.N. ICT and digital libraries / Proceedings of the 7th annual conference on Innovation and technology in computer science education (ITiCSE '02), NY, USA, 2002, p. 237.

9. Lynch C., Henry C., Pritchard S., Humphreys B.L., Schottlaender B. Library leaders on digital libraries and the future of the research library: a panel discussion / Proceedings of the 4th ACM/IEEE-CS joint conference on Digital libraries (JCDL '04), NY, USA, 2004, p. 314.

10. Likhomanov A.V. The policy of library management in the aspect of ensuring security // Theory and practice of preserving books in the library:State. Pub. library Saltykov-Shchedrin, 1999, No. 19, pp. 34-37.

11. Stolyarov Y.N. Protection of the Library Fund: Textbook. Moscow: Fair Press, 2006, 504 p.

12. Arms W.Y. Digital Libraries. Cambridge (Massachusetts); London (England): Publisher:The MIT Press, 2000, 287 p.

13. Oppenheim, Ch. Smithson, D. What is the hybrid library? // Journal of Information science, 1999, vol. 25, № 2, p. 97-112.

14. Lozovich N.A., Orlovskaya S.L. Electronic libraries in the information space (Methodological recommendations). Crimean Republican Institution "Universal Scientific Library after. I. Ya. Franco", Simferopol, 2013, 68 p. http://www.franko.nethouse.ru/static/doc/0000/0000/0161/161836.1k32jbl3i1.pdf

15. Shrayberg Y.L. Libraries in terms of legal and technological evolution of social development processes / Annual report Conf. "Crimea", 2008, Sudak, Moscow, pp. 55-56.

16. Lynn Brindley. Seven approaches to success: the experience and recommendations of the British Library. Translated from English by A.I. Zemskova. Sci. and tech.library, 2009, No 2, pp. 60-76.

17. Khalafova S.A. International programs for the protection of libraries // Library and bibliography: Scientific-theoretical, methodological and practical journal, 2012, № 1 (30), pp. 34-43.14.

18. Bagrova I.Y. Repository storage of library funds // Library Science, 2001, No 2, pp. 19-25.

19. Bagrova, I.Y. Innovation in the work of national libraries of foreign countries: building and reconstruction of buildings // Library Science, 2008, No 6, pp. 100-102.

20. Bagrova, I.Y. Innovation in the work of national libraries of foreign countries: building and reconstruction of buildings // Library Science, 2008, No 6, pp. 100-102. 